\title{
LAS ORGANIZACIONES COMO SISTEMAS SOCIOPOIÉTICOS: METODOLOGÍA Y PRÁCTICA*
}

ORGANIZATIONS AS SOCIOPOIETIC SYSTEM:

METHODOLOGY AND PRACTICE

\section{Marcelo Arnold-Cathalifaud $^{1}$}

RESUMEN: Este artículo presenta una aplicación para describir la organización de las organizaciones basada en un enfoque constructivista, tal como lo desarrolla la Escuela sistémica de Bielefeld, y que da forma a un programa para observar las organizaciones como sistemas sociopoiéticos. La exposición se divide en cuatro secciones: en la primera se despliegan antecedentes que dan sentido a nuestra reflexión sobre las organizaciones, la segunda contiene las bases epistemológicas de nuestras observaciones, y la tercera contempla aplicaciones específicas del programa sociopoiético en las organizaciones. Finalmente, se abordan problemas inherentes a la intervención organizacional, el rol de los agentes en el cambio cultural, sus requerimientos y las proyecciones de la perspectiva propuesta.

Palabras-clave: organizaciones, epistemología, sociopoiesis, sistemas sociales, constructivismo.

[1]Doctor en Sociología, profesor titular de la Facultad de Ciencias Sociales, Universidad de Chile, Santiago de Chile, e-mail: marnold@uchile.cl

* Agradezco los comentarios y sugerencias de Guilherme Brandão. 
ABSTRACT: This paper describes the organization of organizations based on a constructivist approach, as developed by Bielefeld systemic School, and that shapes a program to observe organizations as a sociopoietic systems. The exposition is divided into four sections: the first enlighten antecedents that give meaning to our thinking about organizations, the second contains the epistemological basis of our observations, and the third specific applications of the sociopoietic program in organizations. Finally, we address inherent problems in organizational intervention, the role of agents in cultural change, requirements and projections of this proposal.

Key-words: organizations, epistemology, sociopoiesis, social systems, constructivism

\section{INTRODUCCIÓN}

La evolución de la sociedad marcha de la mano con la generalización de los vínculos sociales de carácter instrumental. Este tipo de relaciones caracteriza a las estructuras que constituyen el componente central del paisaje social contemporáneo: las organizaciones formales, cuyas formas de cálculo racional han terminado por imponerse a las otras formas de vinculación social.

Sólo en la época moderna empieza a generalizarse una catálisis masiva de sistemas sociales organizacionales. Este señal invita a preguntarse por las condiciones para la generalización de las organizaciones y por su carácter de indicador de los procesos de diferenciación que acompañan la monetarización de la economía, la legalización de las relaciones sociales y el traspaso de los mecanismos de inclusión social a posiciones que devienen del paso por el sistema educativo (Luhmann, 1997). Lo anterior destaca que se presuponen ciertas condiciones para que surjan sistemas organizacionales, específicamente: la forma de persona (Luhmann, 1991) y sus respectivas fragmentaciones - roles, competencias y otros equivalentes-; un sis- 
tema económico que proporcione medios monetarios para afectar las motivaciones y garantizar acciones por medio de remuneraciones; la vigencia de contratos vinculados con el sistema jurídico y las operaciones de un sistema que distribuye posiciones sociales sobre la base de habilidades adquiridas y certificadas. Con todo lo anterior se construyen los puestos con los cuales se definen las membrecías organizacionales y se seleccionan a sus miembros.

No es exagerado afirmar que, tomando en cuenta toda su variedad, las organizaciones constituyen hoy el principal entorno social que rodea la vida humana. En forma de fábricas, iglesias, juzgados, partidos políticos, escuelas, laboratorios, museos, organismos internacionales, hospitales o ministerios, las organizaciones participan en las operaciones más significativas de la contemporaneidad.

Las organizaciones se identifican con la capacidad para movilizar, integrar y orientar actividades hacia el cumplimiento de fines, cuyos resultados se observan por su efecto transformador y de agregación de valor. Es en este sentido que las organizaciones tienen incorporada la posibilidad de comunicarse con sus entornos, preferentemente, mediante sus prestaciones de servicios con otras organizaciones. Justamente, la estructuración y coordinación de conjuntos de acciones para cumplir objetivos y el ofrecimiento de soluciones específicas a demandas y problemas difusos, sitúan a las organizaciones como medios eficientes para integrar recursos y enfrentar la reproducción de la sociedad y la de sus entornos.

Constituyéndose como medios fundamentales para cualquier operación significativa en la sociedad, las organizaciones resultan indispensables para la viabilidad de las conciencias y organismos humanos. Aunque se las denuncie por actos irresponsables como degradar la naturaleza, proyectar guerras o mantener inequidades sociales, las expectativas con respecto a la superación o neutralización de estos efectos siempre terminan por extenderse a otras organizaciones. En forma equivalente, en nuestras culturas, la identidad social de los hombres y las carreras personales de cada vez más mujeres, están estrechamente asociadas con el desempeño al interior de 
organizaciones formales. Los empleos no solamente proporcionan aportes económicos, sino que además brindan sujeciones para la identidad personal y, en este sentido, son fuentes importantes para la autorrealización: por ello, su pérdida acarrea remodelaciones importantes en la autoestima. Lo anterior refleja el estrecho acoplamiento entre las organizaciones y las conciencias de las personas, así como de las diferencias entre sus operaciones características - decisiones y pensamientos respectivamente.

No obstante su importancia, y probablemente debido a su diversidad, la unidad de los procesos y las características de los componentes organizacionales son escasamente tratados en la literatura especializada. Ello redunda en que muchos de los problemas e incógnitas organizacionales guardan relación directa con la falta de comprensión de sus operaciones. Por ejemplo, las ciencias de la administración, que ponen su acento en los medios destinados a la consecución de fines, y las disciplinas humanas que destacan la artificialidad de los mecanismos que empalman y someten las acciones de sus membrecías a objetivos que, en principio, les son ajenos, han generado una cantidad importante de libros y conferencias, pero sus aportes no contribuyen a su cabal comprensión. De ahí la frecuente queja de que sus textos y discursos no pueden aplicarse a formas organizacionales que no sean empresas comerciales, es decir, a una variedad específica de las mismas.

La poca claridad y las muchas controversias que suscitan las organizaciones, especialmente cuando se procura optimizarlas, tendrían relación, a nuestro parecer, con las dificultades y complejidades inherentes a sus procesos y con la insistencia en aplicarles miradas y soluciones tradicionales, por ejemplo, intervenirlas cambiando a los individuos y no las redes de relaciones que se constituyen en su interior, o perturbando el todo organizacional optimizando aisladamente sus componentes sin considerar el conjunto del cual forman parte. En este sentido, un aporte a su conocimiento consistiría en explorarlas con teorías sistémicas más abstractas. 
Nuestra comprensión de las organizaciones parte identificando lo que las caracteriza como una clase de sistemas sociales. Ello significa precisar los mecanismos que sostienen las continuidades operacionales que les permiten mantener sus ciclos en medio de entornos dinámicos. Para alcanzar estos propósitos, relacionamos la epistemología constructivista (Bateson, 1976; Schmidt, 1987) con la teoría de los sistemas sociales inspirada en la tradición luhmanniana (1984). Desde esta última perspectiva, que endosamos a la Escuela sistémica de Bielefeld, destacamos a las comunicaciones decisionales como las operaciones constitutivas de las organizaciones, en tanto mediante éstas se definen sus objetivos y metas, los criterios de pertenencia para sus eventuales miembros, la configuración de sus entornos relevantes, los medios con que procesan sus riesgos e incertidumbres, sus formas de estructuración y sus posibilidades de cambio. Esta mirada, que denominamos sociopoiética (Arnold, 2003), conduce nuestro análisis sobre las dimensiones del fenómeno organizacional. Consistentemente, a continuación daremos cuenta de estas condiciones con indiferencia a sus múltiples expresiones y prestaciones, por ejemplo si persiguen o no el lucro.

El programa sociopoiético aborda las organizaciones como sistemas que construyen sus identidades específicas mediante selecciones ininterrumpidas de decisiones. Las organizaciones observan estas operaciones decisionales como comunicaciones y las refieren como medios relacionados con fines. Como sistemas hipercomplejos, las propiedades sinérgicas de las organizaciones, aunque están determinadas internamente, no pueden predecirse ni enseñarse. Con las posibilidades internas, de las cuales dependen, se deslindan de los individuos, construyen sus entornos, se gobiernan y autodiseñan. El entorno puede inducirles reacciones, pero cualquier efecto depende exclusivamente de sus condiciones internas. 


\section{BASES DEL PROGRAMA SOCIOPOIÉTICO DE OB- SERVACIÓN}

Toda comprensión, análisis, diseño, gestión e intervención de las organizaciones se basa en alguna clase de programa de observación, generalmente implícito, que tiene por función describir los mecanismos y operaciones que las caracterizan. Dada la novedad de nuestro enfoque, y siendo concurrente con las teorías sistémicas más conocidas que se aplican a los fenómenos organizacionales, presentaremos, en esta sección, una reseña de sus fundamentos.

El programa sistémico, que antecede al sociopoiético, proviene de la obra de Ludwig von Bertalanffy (1976). Enfrentado a la necesidad de resolver las dificultades del método reduccionista para explicar el fenómeno de la vida, este biólogo constató que sus problemas eran semejantes a los de investigadores de otros campos, y ante ello se abocó a la construcción de una teoría general de los sistemas. Desde otra trayectoria, la cibernética (Wiener, 1948) especializada en los procesos de control y acoplada con sofisticadas teorías de la información que analizan los problemas de la codificación, decodificación, ruidos, canales y redundancias, dio origen a una teoría matemática de la comunicación (Shannon, 1948). De la confluencia de ambos enfoques, y de aportes de otras disciplinas, emergió una renovada forma de entender las organizaciones, en la que se destacan sus dependencias de las condiciones del entorno definiendo sus viabilidades como la mantención de ciclos dinámicos e ininterrumpidos de inputs y outputs (Burns \& Stalker, 1961; Emery \& Trist, 1965; Katz \& Kahn, 1966; Buckley, 1967; Johansen, 1975; Lawrence \& Lorsch, 1973). El logro de este enfoque, hasta la actualidad hegemónico en el campo de la administración, fue inaugurar la producción y el estudio de modelos abstractos para abordar comprensivamente los procesos organizacionales como conjuntos dinámicos de selecciones adaptativas y de control (Forrester, 1961; Aracil, 1986).

Sin embargo, como se aclara con la epistemología constructivista, nuevos medios de observación destacan otras dimensiones 
de los fenómenos. Por ejemplo, la aplicación de distinciones, como retroalimentación positiva y morfogénesis, que aluden a las dinámicas con que se dirigen y autorregulan los sistemas abiertos, puso en relieve las operaciones con las cuales los sistemas, entre ellos las organizaciones, se diferencian y autonomizan de sus entornos (Maruyama, 1968). Estas nuevas ideas llegaron a su máximo despliegue con la noción de autopoiesis, que se hizo conocida a partir de la publicación, a principios de los setenta, del texto de los biólogos chilenos Humberto Maturana y Francisco Varela (1995).

\section{Teoría de la autopoiesis}

El concepto de autopoiesis identifica entidades que tienen por propiedad autorreproducirse construyendo sus componentes por medio de sus propias operaciones. Además, describe sistemas subordinados a su perduración y que se encuentran definidos por sus condiciones estructurales.

Concebir los sistemas como dependientes de sus propias determinaciones, incluyendo lo que consideran información del entorno, hizo perder fuerza a la explicación de sus dinámicas basales como una relación entre causas y efectos o inputs y outputs, es decir, a la idea de sistemas abiertos cuyas operaciones se orientan por su adaptabilidad al entorno. No obstante, debe aclararse que autopoiesis no significa autarquía, pues ningún sistema controla por sí mismo todas las bases de su existencia. Por ejemplo, las organizaciones necesitan a las personas, en tanto cuerpos que viven y conciencias que perciben y piensan, pero estos requisitos solamente permiten la continuidad de sus operaciones, son sus presupuestos y no sus componentes.

A continuación precisaremos algunas premisas de la teoría de la autopoiesis, como explicación biológica, y que son compartidas con el programa sociopoiético que aplicamos a las organizaciones.

Una primera declaración señala que toda referencia a un sistema supone un observador que lo distingue e incluye en una cate- 
goría, por ejemplo como sistema celular, sistema nervioso, sistema psíquico, sistema familiar, sistema cultural, sistema organizacional, etcétera. Observaciones posteriores, apuntando a la clase del sistema indicado, diferencian entre sus operaciones distintivas y su estructura actual. Las primeras designan sus estados posibles en tanto conservan su unidad; la segunda representa la coordinación de sus componentes en uno de sus momentos de actualización. Las implicancias de la distinción son obvias: las estructuras sistémicas son variables, no así sus coordinaciones operativas. Justamente, estas últimas son las que definen a una clase de sistemas. En cualquier caso, la referencia -ineludible - al observador destaca las consecuencias de distinciones con que se identifican distintos grados de complejidad, se distinguen las posibilidades combinatorias entre sus componentes y se calculan los imperativos de selectividad que conllevan sus realizaciones.

Una segunda idea indica que los sistemas autopoiéticos conforman todo lo que les pertenece. Aunque ninguna interacción les es indiferente, sus estados son acordes con sus posibilidades preexistentes; es en este sentido que no responden a mecánicas instructivas. Por ello, cuando hablamos del concepto gatillar nos referimos al desencadenamiento de cambios cuyos alcances están internamente determinados. Específicamente, algunas perturbaciones producen en los sistemas modificaciones que no alteran su organización, y se identifican con su desarrollo y crecimiento, otras provocan cambios que conducen a su colapso y desaparición.

En tercer lugar, en tanto la viabilidad de los sistemas autopoiéticos implica conservar su organización, éstos existen mientras estén adaptados a sus entornos. No es posible observarlo de otro modo - ¡están adaptadas o no existen! Se deduce, además, que si dos o más sistemas interactúan recurrentemente, ello se debe a que se sostienen en coordinaciones mutuamente favorables a sus respectivas reproducciones, es decir, están acoplados estructuralmente.

Finalmente, y en relación con el primer punto, la teoría de la autopoiesis tiene un reglón especial para los procesos cognitivos 
pues, aunque explica que la viabilidad de los sistemas guarda relación con el conocimiento sobre el mundo en el que se desenvuelven, asegura que sus informaciones emergen a partir de la acción de explicar experiencias en un dominio puramente descriptivo cuyas operaciones son cerradas al entorno. En consecuencia, estos sistemas se autoinforman y sus conocimientos -entornos incluidos- son cognitivamente conformados como parte de sí mismos (von Foerster, 1985; Maturana \& Varela, 1995). De acuerdo con lo anterior no habría develamiento de realidad alguna, sino sólo construcción(es) de la misma. A todo sistema productor de conocimiento se le aplica esta condición. Se trata de un constructivismo radical.

Las nociones que conforman la teoría de la autopoiesis y que, originalmente, provienen de las explicaciones sobre el metabolismo celular, suponen enormes rendimientos para explicar el operar de sistemas complejos y como tales han adquirido creciente importancia en la teoría de las organizaciones (Limone \& Cademartori, 1989; Morgan, 1991; Baecker, 1999; Rodríguez, 2001). De hecho, conceptos como clausura operacional, determinismo estructural y acoplamiento estructural son ampliamente aplicados en la descripción de sistemas sociales, especialmente después de su recepción en la teoría sistémica de la sociedad desarrollada por Niklas Luhmann (1984; 1998).

\section{LAS ORGANIZACIONES COMO SISTEMAS SO- CIOPOIÉTICOS}

De acuerdo con Luhmann (1998), la clausura operativa, que refiere el concepto de autopoiesis, se corresponde con una explicación de la sociedad, en tanto se la observe como un sistema que produce como componentes básicos comunicaciones que se generan en sus operaciones de comunicar. Con este enfoque se explica cómo la evolución-complejización de la sociedad, homologada a las comunicaciones, posibilita y desencadena la emergencia de nuevos sistemas sociales (Luhmann, 1998). Entre éstos destacan las organizaciones 
como comunicaciones de decisiones, las interacciones como comunicaciones de temas, los movimientos sociales como comunicaciones de protesta y los sistemas sociales parciales, que emergen de la aplicación de códigos y programas altamente especializados y que caracterizan, entre otras, a las operaciones científicas, económicas y jurídicas. Por ejemplo, las comunicaciones políticas se hacen posibles sobre la base de operaciones recursivas que no dependen de ningún input $u$ output; la justicia pasa a ser asunto del derecho, que traduce lo justo como lo legal; la verdad y los criterios para su determinación, asunto de la ciencia; la belleza se define de acuerdo con los cánones del arte; la certificación de las competencias para la inclusión social quedan en manos de la educación, y así sucesivamente. De esta manera, los procesos evolutivos que caracterizan la modernidad occidental se acompañan con la normalización de sistemas como la religión, la política, la economía, el derecho, la ciencia, la educación, el arte, la medicina y otros, cuya unidad emerge de la autoproducción de los componentes comunicativos mediante los cuales se delimitan. La expresión funcionalmente diferenciada, para referirse a la sociedad contemporánea, destaca el nivel de autonomía alcanzado por tales sistemas (Luhmann, 1998).

En términos específicos, se aprecia la diferenciación de las organizaciones desde el alero de sistemas sociales parciales como el político, económico, religioso, educacional o jurídico, cuando se re-especifican problemas funcionales como el poder, la escasez, la trascendencia, la selección o la legitimidad, hasta hacerlos operables por unidades especializadas de decisión. Por ejemplo, la economía se asume en empresas de diversos tipos, la política en partidos, la justicia en los tribunales, el arte en museos y galerías, las religiones en las parroquias y la ciencia en laboratorios, manteniéndose la condición de que todo sistema puede diferenciarse en otros: para el caso de las organizaciones educativas en parvularios, escuelas, liceos, centros de formación técnica y universidades, o en clínicas, laboratorios, farmacias y consultorios para el caso de la salud. 
Muchas organizaciones, quizá las más grandes e importantes, asumen para sí los códigos y programas del sistema al cual se refieren e intentan "comunicarse" a su nombre, a lo que le siguen las pugnas sobre su efectividad, por ejemplo, si los partidos representan la política o si, efectivamente, persiguen la democracia. La misma sociedad, al desplazar el tratamiento de problemas sujetos a decisiones a organizaciones, se transformó en su entorno y, por efecto recíproco, ocupa organizaciones para poner en marcha operaciones que solamente con éstas se pueden ejecutar y mantener. Sin embargo, dada su especificación, ninguna función social puede ser cubierta completamente por una organización -jla salud no sólo se trata en hospitales o la educación no sólo en escuelas! Por otra parte, una misma organización puede relacionarse con distintos sistemas, como es el caso de las universidades que se debaten entre producir conocimiento mediante la investigación científica, capacitar recursos humanos para el trabajo, formar las élites dirigentes, desarrollar el pensamiento crítico, constituir espacios para la expresión y desarrollo juvenil, autofinanciarse o directamente lucrar a sus inversionistas. Por cierto, tal complejidad repercute en sus crónicas dificultades de gestión.

Luhmann (1978; 1997) desarrolla una teoría general de las organizaciones en el marco de una teoría de la sociedad y que es, por lo tanto, ajena a sus manifestaciones específicas y con ello precisa, de una manera abstracta, cómo estos sistemas se reproducen por medio de operaciones decisorias. En este sentido, construye distinciones que asumen que, aunque la viabilidad de las organizaciones sólo puede consumarse en intercambios energéticos y materiales con el entorno, sus modos de proceder sólo los pueden tomar desde sí mismas -lo cual no garantiza su éxito. En las siguientes secciones explicaremos con más detalle estas ideas integrándolas como reglones específicos al programa sociopoiético aplicado a las organizaciones. 


\section{Operaciones organizacionales básicas}

Si bien por sus orígenes, tipo de prestaciones, diseño y membrecías, toda organización es única e irrepetible, su identidad se alcanza en operaciones que las caracterizan como un tipo de sistema. El aporte de la mirada sociopoiética consiste en describirlas como comunicaciones de decisiones, precisando cómo a través de ellas generan medios con los cuales marcan su diferencia, constituyéndose en una clase propia de sistemas sociales. Ya sea como transnacionales, instituciones no lucrativas, organizaciones de la sociedad civil o empresas del estado, en todas las organizaciones subyacen decisiones que conforman su unidad, desde un horizonte de alternativas, por medio de sus operaciones selectivas.

Las organizaciones emergen como sistemas cuando delimitan sus operaciones, sucesos y tiempos aplicando reflexivamente sus decisiones, es decir, haciendo que éstas actúen sobre sí mismas. Esta autoconectividad libera a las organizaciones de los condicionamientos del mundo y les sirve para definir y sostener sus límites. Es de esta forma que constituyen los espacios que les permiten aplicarse racionalmente a alcanzar las metas que se proponen, sin tener que decidir permanentemente desde el principio. Como se aprecia, los fundamentos de las organizaciones no se encuentran puntualmente en sus fines, en tanto son consecuencias del decidir, aunque con éstos se define la identidad específica que asume su estructura y, en este sentido, cumplen una función reguladora proporcionando posiciones para observar y evaluar decisiones específicas en un contexto más amplio - el cumplimiento de sus fines declarados.

Las organizaciones son sistemas artificiales cuyas formas se van produciendo mediante decisiones que se entrelazan. Como su diferencia específica con respecto a la de otros sistemas sociales reside en que se componen y mantienen mediante las decisiones que producen, la presencia de este tipo de operaciones es condición para cualquier finalidad o estructura organizacional y a través de ellas definen las reglas de inclusión y exclusión con que marcan sus lími- 
tes. Mediante decisiones, las organizaciones absorben incertidumbre "externa" y producen una "interna", y esta incertidumbre autoproducida demanda más decisiones.

Las organizaciones subsisten mientras ocurren las decisiones que les permiten seguir decidiendo, pero como éstas son eventos sin capacidad de perduración, el problema consiste en reproducirlas, para lo cual se requiere de otras decisiones, por ejemplo, las destinadas a evitar que no se cumplan. Reconocer que las decisiones, al producirse a través de otras, no estarían naturalmente disponibles en el entorno, las revela como artefactos organizacionales contingentemente autoproducidos y que siempre deben actualizarse.

Convirtiendo todo aquello que vinculan en decisiones (Luhmann, 1997) las organizaciones aumentan su complejidad, con lo que se obligan a realizar nuevas selecciones mediante otras decisiones. Las decisiones organizacionales se colocan en un contexto de decisiones y producen todo lo que las acompaña, por ejemplo, seleccionado las alternativas frente a las cuales hay que decidir. En este sentido, el balance es siempre más que menos; una vez constituidas, el incremento de su complejidad es más evidente que su reducción. No puede ser de otra manera, su evolución implica seguir adelante, no existen barreras naturales que detengan esos procesos. Los lenguajes burocráticos, aunque no exclusivamente éstos, recuerdan estos procesos de auto-complejización como ciclos dinámicos que obligan a aclarar procedimientos, definir competencias, dictar resoluciones, resolver quejas y conceder permisos atendiendo a reglamentos para aclarar procedimientos, definir competencias, dictar resoluciones, resolver quejas, conceder permisos y así sucesivamente. El ejemplo aclara que la sociopoiesis organizacional no tiene que ver con decisiones adecuadas o inadecuadas para algo o para alguien, sino que remite a cadenas recursivas de operaciones que pueden derivar en condiciones funestas, o incluso graciosas, como las indicadas en la Ley de Parkinson o por el Principio de Peter. Por eso es, también, necesario distinguir que la viabilidad organizacional no es equivalente al reconocimiento social; de hecho, las burocracias han 
resultado muy viables, pero son muy cuestionadas por sus usuarios y miembros.

Las decisiones no son equivalentes entre sí; las más relevantes se aplican sobre otras o definen su interdependencia. Entre éstas destacan los programas destinados a canalizar variados tipos de decisiones, como las filosofías y objetivos organizacionales, las formas para regular estructuralmente las comunicaciones organizacionales, los medios para precisar puestos y tareas definiendo las condiciones y competencias de sus miembros o los recursos para la integración del personal y la gestión de sus motivaciones. La presión de estos procesos se aprecia en la jerarquización, descomposición y fijación de decisiones como precedentes, simultáneas o consecuentes. Premisas como las misiones organizacionales resultan de decisiones explícitas de planificar y, por tanto, regular la complejidad que pueden alcanzar las decisiones potencialmente seleccionables, entre las cuales se encuentra su propia diferenciación estructural y el aumento de sus requisitos de coordinación. Esas aplicaciones, en su conjunto, permiten decidir cómo reespecificar metas y objetivos en nuevas metas y objetivos o, en reversa, englobar fines y metas en otras. Pero, ¿qué papel desempeña la información en la toma de decisiones?

\section{Producción de información}

Las organizaciones no cuentan con pilotos automáticos ni son reguladas por manos invisibles, sino que deben usar sus recursos para enfrentar las turbulencias que acompañan a su gestión y los procesos de autorreflexión sobre sus decisiones forman parte de sus operaciones. Sin embargo, están imposibilitadas de traspasar sus determinaciones estructurales.

En las organizaciones, decidir implica reconocer alternativas, para luego calcular sus consecuencias y finalmente ingresarlas en sus operaciones. Estos procesos abren paso al tema de los riesgos y a su pretensión de reducirlos por la vía del aseguramiento informacional. 
Decidir, desde una referencia informativa, se entiende como un proceso de conversión de los peligros de complejidades abiertas, donde todo es posible, en riesgos de complejidades organizacionalmente formuladas. Su función implica definir espacios seguros donde, al menos, se distinga entre lo de mayor probabilidad y lo altamente improbable, es decir, se reduzca la incertidumbre. Ese desafío generalmente se asume con estudios, por ejemplo, sobre la competencia, las disponibilidades tecnológicas, los perfiles de usuarios o la opinión pública. Paradójicamente, las decisiones que acompañan la producción de información refuerzan el hecho de que los riesgos son inherentes a las organizaciones y van mucho más allá de lo que engloba el concepto de racionalidad limitada (Simon, 1955).

Los procesos de selección de información se expresan tanto en mecanismos organizacionales para reducir sus requerimientos como en aquellos con los que se incrementa la capacidad para procesarlas. Sin poder detener estos procesos decisorios, las organizaciones, como hemos señalado, aumentan ininterrumpidamente su complejidad. Por ejemplo, muchos ejecutivos sufren de ansiedad por la sobrecarga de información potenciada por la digitabilidad de la comunicación y su paso por la red Internet, lo que hace cada vez más difícil informarse sin contar con reglas decisorias para seleccionarla. Por otro lado, gran parte de la gestión directiva se realiza en función de contingencias aceleradas por la falta de tiempo, que obligan a seguir decidiendo sobre efectos que no alcanzan a evaluarse o, incluso, a producirse. No solamente quien decide corre un riesgo, sino que quien no lo hace, debiendo hacerlo, experimenta todo tipo de peligros. Por ejemplo, postergar una decisión puede considerarse como omisión, falta o acierto y podría tratarse como una decisión sobre la cual habrá que decidir. Se trata de la autocomplejización de las operaciones organizacionales, las que, a su vez, desencadenarán nuevas necesidades para su reducción. Como advierte la ley del requisito de la variedad de Ashby (1972): también en estos campos la complejidad debe tratarse con más complejidad. 
Las organizaciones no pueden operar sin la certidumbre que ellas mismas se proporcionan y cuya producción, inicialmente, se constituye especificando sus fines y proyectándolos en las vinculaciones instrumentales que las caracterizan. No obstante, ha muchos efectos no deseados. Las detalladas reglas, formularios, definiciones de cargos, manuales y organigramas que encontramos en algunas organizaciones, impiden observar más allá del margen que ellas trazan o notar algo fuera de lo previsible, pues fijan las referencias para observar sus condiciones. Los mismos fines organizacionales anticipan comunicaciones que deben tomarse en cuenta, es decir, presuponen una organización funcionando. En ese sentido, las certezas autoconstruidas son verdaderos peligros, y entre éstas las referidas al entorno son las más críticas.

El entorno no contiene información, sino que ésta se produce por las selecciones de un observador, en este caso sistemas organizados que la requieren para sus operaciones, pero que sólo pueden autoinformarse sobre sus propias operaciones y las características de sus entornos.

\section{Producción de los entornos}

Sólo desde un sistema se identifica un entorno. Como destaca Baecker (1999), los sistemas son redes de diferencias cuyos límites se corresponden con comunicaciones. Con ellas no solamente construyen su complejidad, sino que también definen la que tratan. Esto quiere decir que, a lo largo de su secuencia de decisiones, las organizaciones especifican su mundo reemplazando su incertidumbre por un modelo interno del mismo (Morgan, 1991).

No obstante su clausura, las organizaciones no carecen de entornos ni tampoco pueden existir sin ellos, pero sólo pueden operar con sus propias reglas. Aunque un observador puede indicar que los entornos son independientes o previos a una organización, no puede rebatir que se definen como relevantes desde la misma. Efectivamente, la absorción de nuevas tecnologías, capitales o conocimien- 
tos depende de sus condiciones internas. Esto no quiere decir que las organizaciones sean indiferentes a lo que ocurre a su alrededor; por el contrario, ignorar indicaciones externas puede perturbarlas seriamente, pero tomarlas en cuenta depende exclusivamente de sus propias determinaciones. Lo anterior refuerza la idea de que no es la adaptación, sino que la mantención de sus operaciones, el principio que guía su viabilidad. La metáfora del gatopardismo tiene en ellas un buen ejemplo: pueden cambiarlo todo para permanecer indemnes.

La práctica administrativa sostiene que las organizaciones responden a necesidades en el entorno como los bomberos a los incendios, los hospitales a los enfermos, los museos a patrimonios que deben ser preservados y así sucesivamente, pero afirmar que las organizaciones se hacen cargo de problemas preexistentes traspasa ideas muy limitadas. En estricto sentido, más cercano a la experiencia es que las organizaciones producen los problemas que las constituyen provocando nuevas necesidades o, como se acostumbra decir, creando mercados y seduciendo auditorios.

Las organizaciones son construcciones y ello incluye sus propios entornos. Muchos problemas aparecen con ellas, por ejemplo, completar encuestas para gozar de garantías de compra, certificar documentos que certifican o acreditar instituciones que acreditan. Para estos casos, y muchos otros, es esperanzador que montañas de "trámites imprescindibles" desaparecen junto con las organizaciones a las que pertenecen.

Las organizaciones producen el entorno mediante selecciones informativas que tienen por función controlar incertidumbres excluyendo posibilidades e incluyendo otras. A raíz de estas operaciones autorreferenciales, los entornos se constituyen simultáneamente con el sistema organizacional que lo indica, ¡nunca antes o después! Esta excéntrica idea puede experimentarse caracterizando organizaciones en términos de sistemas abiertos, para luego eliminar sus corrientes de entradas y salidas. Este ejercicio permite comprender cómo se deben solidariamente a sus entornos. Es evidente que de- 
mandantes de un servicio no surgen independientemente del mismo. No hay consumidores de coca-cola antes de que esa empresa las pusiera a disposición. De hecho, sólo un entorno configurado organizacionalmente puede apreciarse en términos de oportunidades y amenazas. Tales procesos quedan en evidencia, por ejemplo, en las comunicaciones de las Juntas Directivas - ¿cuál ha sido la tendencia del entorno?- o en los procesos de planificación estratégica -¿a quiénes nos dirigiremos? Se entiende, en los casos mencionados, que las organizaciones nunca se refieren al entorno en el sentido tradicional del término, en tanto su visualización se construye mediante sus procesos internos.

Cotidianamente constatamos cómo los responsables de organizaciones confirman sus méritos contabilizando las operaciones que aplican para resolver problemas que ellas mismas configuran. A juicio de los consultores y expertos, estas tendencias a sobreproducir procedimientos y trámites sirven para hacer invisibles las contraindicaciones en sus decisiones. Como destaca Douglas (1996), las organizaciones oscurecen sus responsabilidades e inculpaciones específicas. Incluso, cuando hacen suyas observaciones que aluden a sus debilidades, en sus siguientes pasos, y por sus propias determinaciones, aplicarán sus procesos favoritos: crear más organización, nuevas coordinaciones, crear comisiones o contratar asesores. Sólo observadores de segundo orden (Arnold, 2006), desde el dominio de la búsqueda de explicaciones guiadas por esquemas de distinción extra-esa-organización, pueden dirigirles observaciones tan torturantes. Recordemos, en esta dirección, análisis magistrales como el de Michels (Michels, 1969) frente al funcionamiento de los partidos políticos democráticos o el de Rodríguez (Rodríguez, 1982) sobre las empresas chilenas autogestionadas.

Por cierto, el hecho de que las organizaciones construyan sus entornos no garantiza su perduración. Sus intentos de control no eliminan las posibilidades que excluyen, por el contrario, adormecen su capacidad de respuesta. Lo inobservable no puede ser incluido en sus cadenas de decisiones, aunque esa omisión sea distinguida y eva- 
luada, desde otro ángulo, como amenazante o catastrófica. No hay validez organizacional para eventos externos, por más importantes que puedan ser, salvo que resuenen con sus procesos de decisión. Por ejemplo, cuando proteger el entorno o ser socialmente responsable mejore los negocios, servir al cliente garantice su fidelidad, los estados de ánimo del personal afecten la productividad o una determinada especificidad asegure el financiamiento de sus proyectos, tales oportunidades deben hacerse organizacionalmente operables. Por eso, no es objetable el hecho de que el ejercicio de la responsabilidad social en organizaciones con fines de lucro encuentre su justificación en las consecuencias económicas beneficiosas para la organización, más bien lo contrario sería inexplicable. En este punto, la noción de determinismo estructural no puede desestimarse.

\section{Producción de las personas miembros}

La diferencia entre los individuos y los sistemas organizacionales requiere explicaciones adicionales. De partida, sólo la idea de considerarlos como parte del entorno de los sistemas sociales llama a escándalo (Izuzquiza, 1990).

Pareciera insensato contradecir la experiencia de que sin seres humanos no existen organizaciones sociales de ningún tipo; sin embargo, incluso en los textos más clásicos, aún cuando apelen a personas concluyen que las organizaciones, una vez establecidas, asumen una identidad independiente de las mismas (Blau \& Scott, 1962). De hecho, el reclutamiento de personal es codificado como adquisición de recursos.

Las organizaciones fijan fronteras con los individuos, por cuanto existen diferencias de complejidad, y las prefiguran por medio de sus procesos de selección. Esto significa que para pertenecer y permanecer en ellas es necesario cumplir con determinados requisitos; quien ha sido contratado, hospitalizado o apresado lo sabe bien. Esta condición se aplica aunque se trate de sus fundadores, socios mayoritarios o mandantes. De hecho, las organizaciones no pueden 
absorber la complejidad humana, específicamente su diversidad de intereses, sin amenazar su propia viabilidad. Este orden de inclusión afecta radicalmente la representación interna que existe sobre las personas, que pasan a entenderse como construcciones consustanciales a situaciones sociales que hacen dependientes sus conductas ante los otros y limitan sus repertorios de expectativas (Luhmann, 1991) a los respectivos roles de trabajo. Personas y organizaciones pueden no corresponderse recíprocamente, y la decisión de ser miembro o ser aceptado como tal se juega en una combinación altamente inestable de autoselección con heteroselección.

Las organizaciones se constituyen por relaciones instrumentales coordinadas para alcanzar fines, por lo tanto, las personas son requeridas para llevarlos a cabo, pero no son sus componentes. Esta declaración no implica desvalorarlas, sino que reconocer autorreferencias e identidades anteriores a lo social, pues, al igual que otros sistemas sociales, las organizaciones no producen individuos, solamente los incorporan parcialmente de acuerdo con reglas de selección que remiten a sus propias decisiones. Los sistemas organizacionales también dependen de presupuestos no sociales, por ejemplo, de los sistemas de conciencia, y específicamente de sus rendimientos de percepción. De hecho, la interface entre la comunicación de decisiones y la conciencia de los individuos requiere de sus capacidades de percepción.

La membresía constituye el espacio organizacional, es su lado interno, su lado visible. En este sentido, las organizaciones operan en la exclusión y no en la inclusión total. La admisibilidad a una organización se establece mediante decisiones, que pueden ser sometidas a otras decisiones más adelante, y cuyos efectos consisten en precisar acciones para puestos específicos como los de contador, director, secretario, supervisor, administrativo, operario, auxiliar, diseñador, estudiante y otros equivalentes. Lo anterior tiene por consecuencia que las organizaciones -empresas, universidades, sindicatos, hospitales o ministerios- pueden comprenderse como redes de posiciones diferenciadas y coordinadas mediante decisiones. Para desmarcarse 
de sus miembros, las organizaciones definen los criterios de pertenencia en términos de requisitos, competencias y aportes. Los requerimientos organizacionales implican una drástica reducción de las posibilidades disponibles individualmente para alinearlas con el cumplimiento de los fines organizacionales. Los miembros de una organización deben aceptar desempeñarse de un modo prescrito y no de otro y sólo así serán retribuidos. Desde ese ángulo, las organizaciones no excluyen de la doble contingencia, sino que la tratan de una forma específica, pues cada uno, como individuo, puede seguir actuando como le parezca, pero no dentro de la organización. Con sus mecanismos de inclusión, y luego de evaluación, las organizaciones, si es lo requerido, pueden estructurar la espontaneidad y reglamentar tanto la apariencia como la expresión de los estados de ánimo y gestualidad de su personal, siempre que ello forme parte de sus decisiones. También, por cierto, pueden afectar la salud física y mental de sus miembros. El trabajo de ensamblaje, típico de las cintas de montaje, representa su caricatura. Se trata de acoplamientos que reducen la aceptación del otro manteniendo el control de sus acciones mediante la distribución de satisfactores específicos. Sin embargo, como las condiciones de pertenencia son variables, sujetas a decisión, muchas organizaciones flexibilizan las restricciones de su personal cuando constatan sus efectos positivos. Desde otras referencias las organizaciones son evaluadas según el trato que dan a sus miembros, lo cual puede incidir en su viabilidad comercial.

Salvo en hospitales o centros dedicados al cuidado personal, las organizaciones no prestan mucha atención a los problemas biológicos o psíquicos de sus miembros, a no ser que se reflejen en ausentismo, accidentes laborales o bajas de productividad. Estas experiencias no son incomprensibles, ya que las organizaciones no tienen los mismos intereses que las personas, y ni siquiera los de otros sistemas sociales. Por ejemplo, una de las fuentes de discriminación laboral hacia las mujeres tiene relación con valores culturales muy preciados y estimulados por la sociedad: la maternidad. En esa misma línea, se advierte que empresas autopromocionadas como "grandes familias" 
quizás encubren estrategias que persiguen imponer más exigencias laborales a cambio de menos retribuciones.

Desde el punto de vista de las membrecías, sus acoplamientos con los objetivos organizacionales se manifiestan en el desempeño de puestos de trabajo. Estos empalmes, en el campo laboral, pueden comprender grandes o pequeñas estructuras de acciones; por ejemplo, las actuales disponibilidades cognitivas y tecnológicas permiten que tareas tales como operar una central hidroeléctrica o evaluar la personalidad, requieran fracciones mínimas de las competencias de quienes ocupan los puestos que tienen a su cargo tales trabajos. Lo anterior no quiere decir que la gama más amplia de características personales sean innecesarias para este tipo de organizaciones, aunque debemos prestar atención a que muchas operan con cada vez menos de ellas. En otra dirección, para el desempeño de figuras públicas como comentaristas y políticos se requiere de muchos atributos psicobiológicos definidos como significativos organizacionalmente, pero que, aparentemente, tienen poco que ver con las competencias específicas que se solicitan para el desempeño de tales puestos.

Lo que para la organización significa hacer predecibles los comportamientos de sus miembros para vincularlos con los objetivos organizacionales, es experimentado por las personas como restricciones, iy exigen sus compensaciones! Desde esta perspectiva, las organizaciones no son aceptadas desinteresadamente, por eso el asunto de las retribuciones es fuente de connaturales tensiones y conflictos, cuyo inadecuado manejo se expresa en estrés o en claras indicaciones de una insatisfacción que perturba los estándares organizacionales. Efectivamente, acatar no salirse de los márgenes obliga a definir reparaciones, por ejemplo, dinero, poder, prestigio, buen ambiente, posibilidades de autorrealización o algún otro satisfactor equivalente, aunque debe recordarse que la motivación también responde a escapar del hambre, del aislamiento social o de metas que exigen una excesiva imposición de disciplina. Con esos medios -placenteros o dolorosos- se crean las posibilidades para que, con un mínimo de coacción, se mantengan los aportes, estables y predeci- 
bles, que permitan sustentar las operaciones organizacionales. Estas restricciones organizacionales, finalmente, se logran estableciendo rutinas que se clarifican con líneas estructuradas de poder o, sutilmente, consolidando culturas organizacionales fuertes.

\section{Producción de estructuras}

La complejidad de una organización supone la restricción de las posibilidades de sus componentes, las que son definidas por la estructuración de posiciones sociales y por la producción de redes de expectativas que las sostengan. La membresía como "puestosplanes" se representa en la estructura organizacional y son premisas para las demás decisiones. Por ejemplo, las decisiones de puestos específicos marcan los alcances de las mismas o sólo desde allí pueden decidirse.

Los puentes entre una decisión y otra constituyen, en su momento, las estructuras. Éstas permiten que las decisiones fluyan conectiva y coherentemente en la realización de una organización, pero no representan decisiones irreversibles, siempre están abiertas a modificarse con otras decisiones. Los organigramas (y sus equivalentes), que representan decisiones sedimentadas, establecen un orden que impide que las decisiones partan de cero y restan posibilidades a las actividades decisorias espontáneas sustituyéndolas por procesos organizativos (Simon, 1978). Las típicas formas organizacionales pueden identificarse gracias a diseños que combinan coordinaciones funcionales, departamentalizadas o matriciales, y sus tipos oscilan entre las burocracias rígidas y las poco frecuentes adhocracias (Mintzberg \& McHugh, 1985). Sin embargo las más preparadas para enfrentar sus riesgos no lo hacen blindando las estructuras, sino manteniendo la flexibilidad para decidir sobre otras estructuras. En términos específicos, los diseños organizacionales no solamente precisan relaciones de dominación, sino que además condicionan las decisiones sucesivas de una organización y con ello la preservación o cambio de sus propias formas estructurales. 
La comunicación de las organizaciones se regula mediante la diferenciación, jerarquización y coordinación estructural de sus componentes. La complejidad organizacional implica que no todos sus miembros absorben su reproducción decisional con el mismo vigor. Las decisiones se distribuyen al interior de la organización, ello explica por qué los miembros no reaccionan (deciden) como unidad ante sus problemas, como podría ocurrir en un grupo o en una asamblea. Las jerarquías reducen la complejidad de la comunicación de decisiones en su dimensión vertical y con ello abordan los potenciales conflictos. Por ejemplo, las mayores responsabilidades se asumen en puestos cuyas decisiones, o no decisiones, se orientan al futuro, a los efectos de más largo alcance, como los criterios para seleccionar a los miembros, los procedimientos para enfrentar los conflictos internos y los medios para procesar los contactos de mayor significación organizacional. Solamente en organizaciones hiperparticipativas (cooperativas) o semidemocráticas (universidades públicas) las decisiones importantes son aprobadas por las mayorías. $\mathrm{Al}$ respecto, cuando se proponen escenarios participativos, por ejemplo asambleas, éstos tienen efectos colaterales, pues compartir la responsabilidad de una decisión puede hacerla aún más arriesgada. En síntesis, los esquemas participativos no pueden eliminar los riesgos organizacionales, pero sí requieren que los miembros asuman solidariamente las consecuencias de los errores y con ello difuminan las imputabilidades.

Ninguna organización puede evitar que grupos y comportamientos escapen a sus decisiones. Sus diseños al distribuir y coordinar el poder en las organizaciones tienen por función probabilizar expectativas, pero no aseguran nada en forma definitiva. Aunque se refuercen reglas explícitas que impelan a aceptar y someterse a un determinado orden como requisito para la pertenencia, se requeriría mucho control para que los comportamientos respondieran punto por punto a tales regulaciones organizacionales. En los espacios denominados informales, por ejemplo, predominan las relaciones no controlables por los medios convenidos, la informalidad gatilla la 
necesidad de mayores, y más eficientes, mecanismos que aseguren las condiciones requeridas para la continuidad de las operaciones organizacionales. No obstante, estos entornos internos no siempre son perturbadores, su presencia puede ser evaluada como un capital para el mejoramiento de sus climas organizacionales incluso, algunas organizaciones, los promueven deliberadamente efectivizándolos como caminos rápidos para la solución de emergencias o para abordar problemas poco frecuentes. Así, las estructuras informales pueden ser tanto funcionales como disfuncionales al cumplimiento de los propósitos organizacionales, lo que nos importa destacar es que obedecen a una sociogénesis distinta.

\section{Intervención organizacional}

Más que nunca antes, en la sociedad contemporánea las organizaciones conservan su viabilidad evolucionando; el dinamismo y no el equilibrio es su estado óptimo. Operan cambiando permanentemente, y pocas veces ello se trata sólo de agregar más de lo mismo. En este sentido, importa considerar que las organizaciones siempre se están autointerviniendo, en tanto están en permanente cambio. Lo que es adecuado en un momento no lo es en otro. De hecho, cuando sus directivos suponen conocer todo lo que requieren, significa que la organización perdió su dinamismo y empezó su decadencia. Crecer simplemente agrandando estructuras organizacionales, utilizando soluciones que sirvieron alguna vez o dando por verdaderos supuestos que alguna vez lo fueron, tampoco es muy buena garantía. Lo que tiene armonía y proporción en una escala, puede no tenerlos en otra, como lo ilustró el antropólogo Bateson (1993) en su famosa narración sobre el lamentable caballo poliploide.

Desde la perspectiva sociopoiética, las dificultades para cambiar planificadamente estructuras o estilos de conducción en las organizaciones se comprenden con la noción de clausura operativa. Lo anterior destaca que los componentes organizacionales se pueden perturbar desde el entorno, pero sólo con sus exclusivas e insusti- 
tuibles operaciones decisionales se pueden discriminar, distinguir e implementar con éxito propuestas nuevas.

Las intervenciones organizacionales que tienen por objeto fortalecer capacidades internas parten por decidir observar sus procedimientos para la toma de decisiones. Sus principios atienden al hecho de que los cambios organizacionales se relacionan directamente con la capacidad de autoobservación y con las habilidades de agentes de cambio para desplegarlas, para lo cual irritan, en grados relevantes, las dinámicas organizacionales autorreferenciales. Tema secundario es referirse al nivel y profundidad de los cambios organizacionales desencadenados, si se trata de proyectar distinciones que apoyan premisas organizacionales en uso en nuevos espacios o de elaborar nuevas premisas para aplicar a los mismos espacios.

La perspectiva sociopoiética permite comprender que el fracaso de los modelos organizacionales no se debe, exclusivamente, a resistencias al cambio, a la falta de pericia directiva, a incomprensiones del personal que "no se pone la camiseta" u otro tipo de "incompetencias", sino que a la opacidad de las estructuras sistémicas, en este caso organizacionales, que condicionan tales respuestas. En tanto intervenir organizaciones consiste en movilizar las posibilidades disponibles, el rol para un consultor, como agente de cambios, es de facilitador, alguien que promueve la comunicación autorreflexiva con interrogantes tales como: ¿por qué decidimos así? o ¿por qué hemos tomado esas decisiones? Es evidente que una consultoría, de este tipo, tiene por función principal dinamizar las organizaciones sometiendo sus observaciones a nuevas observaciones, pero no cuenta con medios para producir cambios específicos, pues las operaciones organizacionales están limitadas por su operar autoclausurado. Por eso, las propuestas de cambios organizacionales a veces resultan y otras no, independientemente de cuán bien funcionaron o funcionan para otros en otras partes. Como destacó von Foerster (1993), el comportamiento de sistemas no triviales no se puede predecir a partir del conocimiento de los estímulos que se les dirigen. 
Las intervenciones sociopoiéticas dan por sentado que las organizaciones se componen de decisiones, que son conducidas por marcadores internos y que sus posibles cambios de estado están predeterminados. Lo anterior quiere decir que las organizaciones reaccionan sólo si sus condiciones -ique han ido elaborando decisionalmente! - se lo permiten, y, cuando lo hacen, reespecifican los efectos de acuerdo con sus posibilidades del momento. Aunque se encuentren en acoplamiento estructural con sus entornos, sólo en ellas se establecen sus estados probables, y sólo desde ellas se definen los criterios que hacen posible su intervención. Esto significa que la única forma de orientar cambios organizacionales consiste en afectar sensibilidades estructuralmente condicionadas alterando sus comunicaciones. Estos procesos ocurren naturalmente, el problema es cómo actuar planificadamente sobre ellos.

La capacidad estratégica de un agente de cambio proviene de su condición de observador en un plano de segundo orden. Sus acciones consisten en incrementar la variedad organizacional interna gatillando sucesos que impulsen a generar posibilidades no consideradas o anteriormente negadas. Gatillar implica estimular niveles de complejidad y autoorganización para aprovechar mejor sus condiciones de autorreferencialidad. Con tal objeto irritan, con distinciones, los esquemas de distinciones que subyacen a las comunicaciones organizacionales exponiéndolos y colocándolos en cuestión de tal manera que la organización percibe en su propia pantalla perturbaciones, ambigüedades, decepciones, desviaciones e inconsistencias que pueden, o no, desencadenar modificaciones estructurales en direcciones previstas. Por lo anterior, los cambios desde dentro del sentido organizacional, es decir, sobre su fondo cultural, pueden suponerse con mayores posibilidades de culminar con éxito, pues sólo se consideran como alternativas aquellas que son posibles de visibilizar desde las mismas organizaciones.

Los consultores sólo facilitan la reintroducción en la comunicación de opciones invisibles para el sistema organizacional para, 
con ello, aumentar su variedad y alternativas de selección, pero no seleccionan por ella.

Favorecer la complejización incrementando la variedad organizacional asegura viabilidad ante un mundo siempre ignoto. Movilizar nuevas capacidades de observación, y multiplicar distintos planos para que sean tomados en cuenta, demanda competencias para la autoobservación y autorreflexión. La regla es que una organización es capaz de enfrentar el cambio cuando puede aprender, a partir de su autorreconocimiento, a ser distinta de lo que es. En este plano se aprecian recursos ejemplares, por ejemplo, la afectación de sus premisas de decisiones mediante la planificación estratégica (Hax \& Majluf 1993); intervenciones comunicacionales como las propuestas por Flores (1994), así como la producción de nuevos escenarios que se estimulan con ejercicios de visualización (Cuducio, 1992). También las condiciones de autoobservación y apertura a los cambios pueden activarse con el diseño de estructuras matriciales que permiten asumir muchos estados a sus componentes y a las relaciones entre éstos, los que, a su vez, les permiten operar con mayores grados de indeterminación. Desarrollar mecanismos para el autoaprendizaje siempre implica reforzar principios de autoorganización con dispositivos de retroalimentación.

En tanto las decisiones organizacionales quedan sujetas a las determinaciones propias de todo proceso comunicativo, parte de la actual industria de la consultoría -recogiendo la experiencia- se ha orientado a promover comunicaciones reflexivas (Senge, 1995). Muchos consultores dedicados al couching, que integran sus experiencias provenientes de la ingeniería, la administración, la psicología, las ciencias sociales y la filosofía del lenguaje (Flores \& Winograd, 1989; Echeverría, 1996), interpretan las intervenciones como cambios cognoscitivos que tienen por objetivo ampliar los horizontes comunicativos al interior de las organizaciones devolviendo contingencia a las decisiones y a las premisas que las sustentan. Es decir, movilizando los cambios que son posibles. 
Sin embargo, los cambios organizacionales se generan desde su propio sustento, no es posible intervenir si no están dadas las posibilidades. Sólo se pueden distinguir e implementar las modificaciones esperadas cuando éstas se incluyen en sus cadenas de decisiones. La regla es que sólo las perturbaciones que sintonizan con las operaciones organizacionales tienen posibilidades de éxito. Por eso, los sucesos desencadenados por una intervención llevan a una secuencia de reacciones previstas sólo cuando existen condiciones favorables. El consultor debe, por lo tanto, desenvolverse a partir de las condiciones preexistentes. En este sentido, la solicitud de consultoría es una decisión y su remisión a mejoramientos también lo es, por lo tanto, ya desde allí se revelan sus propias posibilidades.

\section{PROYECCIONES DEL PROGRAMA SOCIOPOÉTICO}

Mientras la ciencia social procesa nuevos conocimientos, la responsabilidad de mejorar las gestiones organizacionales adquiere inusitada urgencia. El siglo veintiuno abre paso al requerimiento ético de entender su funcionamiento, por cuanto dependemos cada vez más de sus prestaciones para responder a necesidades que ya no pueden satisfacerse por otros medios. La sociedad misma, aquella de la cual se catalizaron, es la que requiere organizaciones eficientes, eficaces y con impacto social. Especial relevancia guarda para nosotros la innegable importancia que tienen sus diferentes variedades para los procesos de modernización, democratización y equidad social. Por eso, no obstante los avances en la comprensión de las organizaciones, queda mucho por hacer. Mientras las investigaciones sobre sus operaciones distintivas están en sus inicios, irrumpen los procesos de despersonalización, deslocalización y destemporalización de sus actividades a través de la red Internet. Estas nuevas condiciones, todas ellas comunicacionales, pueden colocar en crisis hasta los más novedosos modelos teóricos que no las consideren como su centro.

Sin duda, al cuestionar fórmulas que se adscriben a otros paradigmas, la perspectiva sociopoiética abre paso a nuevas reflexiones 
sobre las organizaciones y sus propiedades específicas. Es en este sentido que estrechar relaciones entre el conocimiento, que surge de la investigación y reflexión científica, y las necesidades prácticas de la administración, gestión y consultoría organizacional, no es un asunto menor, especialmente en contextos que mueven a la búsqueda de recetas rápidas o que, no obstante sus fundamentos, pecan de excesivo voluntarismo (Dávila \& Maturana, 2007). Finalmente, enfrentarse a teorías que cuestionan presupuestos dados tradicionalmente genera resistencias e inevitablemente conduce a interrogarse acerca de la utilidad del esfuerzo, pero desarrollar nuevos puntos de vista para ampliar la comprensión de las organizaciones también conlleva nuevas exigencias. Valgan estas últimas observaciones como justificativo para el nivel de abstracción de nuestra presentación y de las interrogantes que deja abiertas a sus lectores.

\section{REFERENCIAS}

ARACIL, J. Introducción a la dinámica de sistemas. Madrid: Alianza Editorial Textos, 1986.

ARNOLD, M. “Antropología social aplicada en organizaciones económicas y participacionales". Revista Chilena de Antropología, n 10, pp. 81-97, 1991.

. "Fundamentos de la observación de segundo orden". In: Metodologías de investigación social. Introducción a los oficios. Manuel Canales Cerón (coordinador-editor). Santiago de Chile: Editorial LOM, 2006, (pp. 321-348).

"Fundamentos del Constructivismo Sociopoiético".

Cinta de Moebio, $\mathrm{n}^{\mathrm{o}}$ 18, disponible en http://www.facso.uchile.cl/ publicaciones/moebio/18/arnold.htm, en 2003.

ASHBY, W. R. Introducción a la Cibernética. Buenos Aires: Ediciones Nueva Visión, 1972. 
BAECKER, D. Organisation als System. Frankfurt am Main: Suhrkamp Verlag, 1999.

BATESON, G. Pasos hacia una ecología de la mente. Buenos Aires: Ediciones Carlos Loé, 1976. . Espíritu y Naturaleza. Buenos Aires: Amorrortu editores, 1993.

BERTALANFFy VON, L. Teoría general de los Sistemas. México: Editorial Fondo de Cultura Económica, 1976.

BLAU, P. \& SCOTT, W. R. Formal Organizations. Chandler Publishing Co., 1962.

BUCKLEY, W. La sociología y la teoría moderna de los sistemas. Buenos Aires: Amorrortu Editores, 1973.

BURNS, T. \& STALKER, G. M. The Management of Innovation. London: Tavistock Publisher, 1961.

CUDUCIO, C. PNL y Comunicación. Barcelona, España: Ediciones Granica S.A., 1992.

DÁVILA, X. \& MATURANA, H. "La gran oportunidad: fin de la psiquis del liderazgo en el surgimiento de la psiquis de la gerencia coinspirativa”. Estado, Gobierno y Gestión Pública. Universidad de Chile: Revista de Administración Pública, $\mathrm{n}^{\circ}$ 18, 2007.

DOUGLAS, M. La aceptabilidad del riesgo según las ciencias sociales. Barcelona: Editorial Paidós, 1996.

ECHEVERRÍA, R. Ontología del Lenguaje. Santiago, Chile: Ediciones Dolmen, 1996.

EMERY, F. E. \& TRIST, E. L. "The causal Texture of Organizational Environment". Human Relations, Vol 18, pp. 21-31, 1965.

FLORES, F. Inventando la empresa del siglo XXI. Santiago, Chile: Hachette, 1989.

FLORES, F. \& WINOGRAD, T. Hacia la comprensión de la Información y la Cognición. Barcelona: Colección ESADE, 1989. 
FOERSTER VON H. Wissen und Gewissen: Versuch einer Brücke. Frankfurt am Main: Suhrkamp Verlag, 1993.

Sicht und Einsicht. Versuche $\mathrm{zu}$ einer operativer Erkenntnistheorie. Braunschweig - Wiesbaden: Vieweg, 1985.

FORRESTER, J. W. Industrial dynamics. Portland, Oregon, 1961.

HAX, A. \& MAJLUF, N. Gestión de empresa con una visión estratégica. Santiago de Chile: Ediciones Dolmen y Ediciones Pedagógicas Chilenas S.A., 1993.

IZUZQUIZA, I. La sociedad sin hombres. Niklas Luhmann o la teoría como escándalo. España: Editorial Anthropos, 1990.

JOHANNSEN, O. Introducción a la Teoría General de Sistemas. Facultad de Economía y Administración, Universidad de Chile, 1975.

KATZ, D. \& KAHN, J. K. The social psychology of organizations. New York: John Wiley and Sons Inc., 1966.

LAWRENCE, P. \& LORSCH, J. Organización y ambiente. Barcelona: Editorial Labor, 1973.

LIMONE, A. \& CADEMARTORI, D. La empresa, una red de transformaciones. Santiago de Chile: Editorial Jurídica Cono Sur Ltda., 1989.

LUHMANN, N. Organisation und Entscheidung. Westdeutscher: Verlag Opladen, 1978.

Soziale Systeme: Grundrisse einer allgemeinen Theorie. Frankfurt am Main: Suhrkamp Verlag, 1984.

. “Die Form Person”. Soziale Welt, n42, pp. 166-175, 1991.

. Organización y Decisión. Autopoiesis, acción y entendimiento comunicativo. México: Universidad Iberoamericana y Anthropos, 1997. 
Die Gesellschaft der Gesellschaft. Frankfurt am Main,

Suhrkamp taschenbuch wissenschaft 1360, Suhrkamp Taschenbuch Verlag, 1998.

MARUYAMA, M. “The second cybernetics: deviation amplifying mutual causal processes“. In: BUCKLEY, W. (Ed.). Modern Systems Research for the Behavioral Scientist. Aldine, Chicago, 1968. (pp. 304-313).

MATURANA, H. \& VARELA, F. De máquinas y seres vivos. Autopoiesis: la organización de lo vivo. Santiago de Chile: Editorial Universitaria, Colección El Mundo de las Ciencias, 1995.

MICHELS, R. Los partidos políticos. Un estudio sociológico de las tendencias oligárquicas de la democracia moderna. Buenos Aires: Editorial Amorrortu, 1969.

MINTZBERG, H. \& MCHUGH, A. "Strategy formation in an adhocracy”. Administrative Sciencie Quartely, vol 30, n 2, pp. 160-197, 1985.

MORGAN, G. Imágenes de la Organización. México: Ediciones Alfaomega S.A., 1991.

RODRÍGUEZ, D. Formación de oligarquías en procesos de autogestión. Instituto de Sociología, Universidad Católica de Chile, 1982.

- Gestión Organizacional: Elementos para su estudio. Ediciones Universidad Católica de Chile, 2001.

SCHMIDT, S. Der Diskurs des Radikalen Konstruktivismus. Frankfurt am Main, Suhrkamp taschenbuch wissenschaft, 1987.

SENGE, P. La Quinta Disciplina en la Práctica. Barcelona, España: Ediciones Granica S.A., 1995.

SHANNON, C. „A mathematical theory of communication“. Bell Syst. Techn. no 27, pp. 379-423, 1948. 
Las organizaciones como sistemas sociopoiéticos: metodología y práctica

SIMON, H. A. El comportamiento administrativo. Estudio de los procesos de adopción de decisiones en la organización administrativa. Madrid: Aguilar, 1978.

SIMON, H. A. “A Behavorial Model of Rational Choice”. Quarterly Journal of Economics, no 69, pp. 99-118, 1955.

WIENER, N. Cybernetics. New York: Willey, 1948.

Recebido em: 29/03/2012

Aprovado em: 31/05/2012 